\title{
Analisis Pengaruh Supervisi dan Kompetensi Terhadap Kinerja Guru SMP Negeri 1 Bekasi Tahun Ajaran 2016/2017
}

\author{
Elvi Hidayati \\ SMK NEGERI 4 PEKANBARU \\ Corresponding author's: elvihidayati@ymail.com
}

\section{Analysis of the Influence of Supervision and Competence on Teacher Performance of SMP Negeri 1 Bekasi 2016/2017 Academic Year}

\section{Article info: \\ Article History Available online 30 September 2018}

Keywords: Supervision, Competence, Teacher Performance

\begin{abstract}
Abstrak
Penelitian ini bertujuan untuk mendapatkan informasi secara faktual dan konseptual tentang pengaruh supervisi dan kompetensi terhadap kinerja guru. Teknik yang digunakan adalah teknik observasi atau survey dengan menggunakan daftar pertanyaan (kuesioner) terhadap guru SMP Negeri 1 Bekasi. Daftar pertanyaan dibuat secara terstruktur dengan menggunakan Skala Likert. Sampel yang diambil sebanyak 32 responden. Hasil survey dan hasil pengolahan data yang dilakukan dengan SPSS. 19.0 diperoleh hasilhasil penelitian sebagai berikut: (1) Secara simultan supervisi dan kompetensi berpengaruh positif, relatif kuat dan signifikan terhadap Kinerja guru SMP Negeri 1 Bekasi. Hal tersebut ditunjukkan dengan perolehan R-Square sebesar $68 \%$. Kemudian, secara parsial supervisi berpengaruh positif, relatif cukup kuat dan signifikan terhadap kinerja guru pada SMP Negeri 1 Bekasi. Hal tersebut ditunjukkan dengan perolehan R-Square sebesar $55 \%$. (2) Secara parsial kompetensi berpengaruh positif, relatif kuat dan signifikan terhadap kinerja guru pada SMP Negeri 1 Bekasi. Hal tersebut ditunjukkan dengan perolehan $R$-Square sebesar $62 \%$
\end{abstract}

\begin{abstract}
:
This study aims to obtain factual and conceptual information about integration and teacher performance. The technique used is a survey technique using a list of questions (questionnaires) for teachers of SMP Negeri 1 Bekasi. A list of comments is made using a Likert Scale. A sample of 32 respondents. Survey results and data processing results are carried out with SPSS. 19.0 get search results as follows: (1) Simultaneously supervision and positive competence, are relatively strong and significant towards the performance of teachers of SMP Negeri 1 Bekasi. This was recorded with the acquisition of R-Square by $68 \%$. Then, partially positive supervision, relatively strong and significant towards the performance of teachers in SMP Negeri 1 Bekasi. This is by using $R$-Square by $55 \%$. (2) Partially positive competence, relatively strong and significant to the performance of teachers in SMP Negeri 1 Bekasi. This is by using $R$-Square by $62 \%$
\end{abstract}




\section{PENDAHULUAN}

Tidak bisa diingkari bahwa, sumber daya manusia adalah penentu keberhasilan suatu negara dalam melakukan pembangunan nasional. Oleh karenanya sektor pendidikan nasional adalah sektor yang sangat signifikan untuk diperhatikan. Menurut UU No.20 tahun 2003 tentang Sistem Pendidikan Nasional bahwa pendidikan adalah usaha sadar dan terencana untuk mewujudkan suasana belajar dan proses pembelajaran agar peserta didik secara aktif mengembangkan potensi dirinya untuk memiliki kekuatan spiritual keagamaan, pengendalian diri, kepribadian, kecerdasan, akhlak mulia, serta ketrampilan yang diperlukan dirinya, masyarakat, Bangsa dan Negara.

Untuk mewujudkan tujuan pendidikan nasional sebagaimana dikemukakan diatas, peran guru atau tenaga pendidik mutlak diperlukan. Dalam pelaksanaan fungsi dan tugasnya, guru sebagai profesi menyandang persyaratan tertentu sebagaimana tertuang di dalam UU Republik Indonesia Nomor 20 tahun 2003 tentang Sistem Pendidikan Nasional. Dalam pasal 39 (1) dan (2) dinyatakan bahwa: Tenaga kependidikan bertugas melaksanakan administrasi, pengelolaan, pengembangan, pengawasan, dan pelayanan teknis untuk menunjang proses pendidikan pada satuan pendidikan. Pendidik merupakan tenaga profesional yang bertugas merencanakan dan melaksanakan proses pembelajaran, menilai hasil pembelajaran, melakukan pembimbingan dan pelatihan, serta melakukan penelitian dan pengabdian kepada masyarakat, terutama bagi pendidik pada perguruan tinggi.

Untuk dapat melaksanakan tugas dan tanggung jawab diatas, seorang guru dituntut memiliki beberapa kemampuan dan ketrampilan tertentu. Kemampuan dan ketrampilan tersebut sebagai bagian dari kompetensi profesionalisme guru. Kompetensi merupakan suatu kemampuan yang mutlak dimiliki oleh guru agar tugasnya sebagai pendidik dapat terlaksana dengan baik.

Tugas guru erat kaitannya dengan peningkatan sumber daya manusia melalui sektor pendidikan, oleh karena itu perlu upaya-upaya untuk meningkatkan kinerja guru untuk menjadi tenaga profesional, agar peningkatan mutu pendidikan dapat berhasil. Sebagaimana dikemukakan oleh Tilaar (1999) peningkatan kualitas pendidikan tergantung banyak hal, terutama mutu gurunya.

Kinerja guru atau prestasi kerja adalah suatu hasil kerja yang dicapai seseorang dalam melaksanakan tugas yang dibebankan kepadanya yang didasarkan atas kecakapan, pengalaman, dan kesungguhan serta waktu (Hasibuan, 2001). Kinerja guru akan baik jika guru telah melakukan unsur-unsur yang terdiri dari kesetiaan dan komitmen yang tinggi pada tugas mengajar, menguasai dan mengembangkan bahan pelajaran, kedisiplinan dalam mengajar dan tugas lainnya, kreativitas dalam pelaksanaan pengajaran, kerjasama semua warga sekolah, kepemimpinan yang menjadi panutan siswa, kepribadian yang baik, jujur dan objektif membimbing siswa, serta tanggung jawab terhadap tugasnya, karena itu tugas kepala sekolah selaku manager adalah melakukan penilaian kinerja guru.

Ada beberapa hal yang menyebabkan meningkatnya kinerja guru, namun penulis mencoba mengkaji masalah supervisi yang diberikan oleh kepala sekolah dan kompetensi guru. Supervisi dalam hal ini adalah mengenai tanggapan guru terhadap pelaksanaan pembinaan dan bimbingan yang diberikan oleh kepala sekolah yang nantinya berdampak kepada kinerja guru yaitu kualitas pengajaran. 
Sikap professional guru merupakan hal yang amat penting dalam memelihara dan meningkatkan profesionalitas guru,karena selalu berpengaruh pada perilaku dan aktivitas keseharian guru. Perilaku profesional akan lebih diwujudkan dalam diri guru apabila institusi tempat ia bekerja memberi perhatian lebih banyak pada pembinaan, pembentukan, dan pengembangan sikap profesional (Pidarta, 1996).

Berdasarkan hasil observasi dan wawancara yang dilakukan dengan beberapa guru di SMP Negeri I Bekasi, ditemukan bahwa SMPN I Bekasi telah berhasil menjadi sekolah favorit tidak hanya di Kota Bekasi, namun berbagai prestasi telah di capai juga di tingkat nasional. Keberhasilan pendidikan di SMPN Bekasi ini, selain disebabkan oleh seleksi penerimaan siswa baru yang sangat ketat juga tidak terlepas dari peran Guru, Staf Tata Usaha dan Kepala Sekolah dalam melakukan proses belajar mengajar di sekolah, keberhasilan ini juga didukung oleh kelengkapan fasilitas yang memadai sebagai sekolah yang berstandar Internasional.

SMPN I memiliki tenaga pengajar yang bersertifikasi, selain itu Kepala Sekolah juga mendukung upaya-upaya untuk meningkatkan kompetensi para guru. Kepala sekolah melakukan supervisi dengan baik. Dengan melakukan supervisi Kepala sekolah telah membantu guru-guru melihat dengan jelas tujuan pendidikan dan berusaha mencapai tujuan pendidikan itu dengan membina dan mengembangkan metode-metode dan prosedur pengajaran yang lebih baik. Selain itu, Kepala sekolah juga mendukung upaya-upaya peningkatan kompetensi guru di SMPN I Bekasi.

Supervisi ialah suatu aktivitas pembinaan yang direncanakan untuk membantu para guru dan guru sekolah lainnya dalam melakukan pekerjaan mereka secara efektif. Fungsi supervisi atau pengawasan dalam pendidikan bukan hanya sekadar kontrol, melihat apakah segala kegiatan telah dilaksanakan sesuai dengan rencana atau program yang telah digariskan, tetapi lebih dari itu. Supervisi dalam pendidikan mengandung pengertian yang luas. Kegiatan supervisi mencakup penentuan kondisikondisi atau syarat-syarat personel maupun material yang diperlukan untuk terciptanya situasi belajar-mengajar yang efektif, dan usaha memenuhi syarat itu. Seperti dikatakan oleh Nealey dan Evans dalam bukunya, "Hand book for effective supervision of instruction", seperti berikut: "...the term 'supervision' is used to describe those activities which are primarily and directly concerned whit studying and improving the conditiaons which surround the learning and groeth of pupils and teachers".

Pengertian kompetensi dapat dijelaskan secara sederhana sebagai kemampuan manusia yang ditemukan dari praktek dunia nyata dapat digunakan untuk membedakan antara yang sukses (superior) dengan yang biasa saja di tempat kerja (Kennedy P, 1995).

Kompetensi seseorang dapat di tunjukkan dengan hasil kerja atau karya, pengetahuan, ketrampilan, perilaku, karakter, sikap, motivasi atau bakatnya, membedakan penyanyi dan pelukis yang superior dengan rata-rata, misalnya, dapat dilihat dari karyanya, yaitu album dan lukisannya. Sedangkan untuk membedakan juru taksir dengan ("appraisal") superior dengan rata-rata yang tugas utamanya memberikan estimasi harga suatu barang adalah pengetahuannya akan harga barang. Sedang yang membedakan tukan las superior ("over head welder") dengan yang ratarata adalah ketrampilannya menggunakan peralatan las untuk posisi yang dan tempat kerja yang sangat sulit mesalnya kemampuan me-las untuk posisi diatas kepala. Dari contoh diatas ditemukan bahwa yang membedakan antara mereka yang bekerja 
superior dengan yang rata-rata bukan semata tingkat intelegensia dan nilai akademis yang dimiliki.

Spencer (2001) mendefinisikan kompetensi "an underlying characteristic of individual that is causally related to criterion-referenced effective and/or superior performance in a job or situation". Sebagai karakteristik individu yang melakukan kompetensi merupakan bagian dari kepribadian individu yang relative dalam dan stabil, dapat dilihat dan diukur dari perilaku individu yang bersangkutan ditempat kerja atau dalam berbagai situasi. Untuk itu kompetensi seseorang mengindikasikan kemampuan berperilaku seseorang dalam berbagi situasi yang cukup konsisten untuk suatu periode waktu yang cukup panjang dan bukan hal yang kebetulan sesaat semata. Kompetensi memiliki persyaratan digunakan untuk menduga atau terbukti secara empiris merupakan penyebab suatu keberhasilan. Dimana keberhasilan perilaku atau kinerja ini secara akademis didasarkan pada criteria ukuran keberhasilan sebagai standar kinerja yang dapat diterima secara bisnis maupun social.

Istilah kinerja guru berasal dari kata job performance/actual permance (prestasi kerja atau prestasi sesungguhnya yang dicapai oleh seseorang). Jadi menurut bahasa kinera bisa diartikan sebagai prestasi yang nampak sebagai bentuk keberhasilan kerja pada diri seseorang. Keberhasilan kinerja juga ditentukan dengan pekerjaan serta kemampuan seseorang pada bidang tersebut. Keberhasilan kerja juga berkaitan dengan kepuasan kerja seseorang.

Prestasi bukan berarti banyaknya kejuaraan yang diperoleh guru tetapi suatu keberhasilan yang salah satunya nampak dari suatu proses belajarmengajar. Untuk mencapai kinerja maksimal, guru harus berusaha mengembangkan seluruh kompetensi yang dimilikinya dan juga manfaatkan serta ciptakan situasi yang ada dilingkungan sekolah sesuai dengan aturan yang berlaku.

\section{METODE PENELITIAN}

Penelitian ini menggunakan metode penelitian survei dengan pendekatan explanatory analisis dan prediktif, yang bertujuan untuk mengetahui hubungan dan pengaruh antara variabel bebas dan terikat. Selanjutnya hasil penemuan akan dideskripsikan, yaitu dengan melakukan pengamatan dan penelitian serta menggambarkan sifat atau peristiwa yang tengah berlangsung pada saat penelitian dilakukan dan memeriksa sebab-sebab dari gejala tertentu (Travers, 2001). Dalam penelitian ini mengkaji hubungan dan pengaruh supervisi dan kompetensi berpengaruh terhadap kinerja guru SMPN 1 Bekasi. Fenomena tersebut dapat didesain melalui fungsi matematis berikut :

$$
\begin{aligned}
& \hat{Y}=F\left(X_{1}, X_{2} \ldots \ldots .+X n\right) \text { model persamaan multivariat, dengan } \\
& \hat{Y}=F(X) \text {, model persamaan bivariat. }
\end{aligned}
$$

Desain model penelitian ini adalah bahwa secara simultan supervisi dan kompetensi terhadap kinerja guru SMPN 1 Bekasi, demikian pula pada hubungan masing-masing variabel bebas terhadap variabel terikat (kinerja guru).

Penelitian ini akan dilakukan di SMPN I Bekasi yang beralamat di Jalan KH. Agus salim No. 138, Kota Bekasi, Jawa Barat, 17112. 


\section{HASIL DAN PEMBAHASAN}

Berdasarkan penelitian pada bab-bab sebelumnya serta data-data yang diperoleh, maka untuk dapat menentukan apakah benar variabel supervisi dan kompetensi dapat dijadikan pengukuran terhadap peningkatan kinerja guru SMPN I Bekasi, namun sebelum data di olah terlebih dahulu dilakukan pengujian terhadap variabel yang digunakan yaitu kompetensi dan kompetensi untuk mengetahui apakah data tersebut akurat dan dapat dipercaya. Untuk lebih jelasnya maka

Hasil pengolahan data dengan program SPSS 19.0 menunjukkan, bahwa ternyata variabel supervisi dan kompetensi secara simultan mampu memberikan kontribusi yang relatif kuat, positif dan signifikan terhadap kinerja guru.

Berdasarkan hasil pengujian statistik diperoleh hasil perhitungan koefesien regresi, pada tampilan model simultan $\hat{Y}=7.289+0.381(X 1)+0.532(X 2)+e$, dari persamaan berganda (simultan) terlihat arah hubungan yang dihasilkan dari variabel bebas terhadap variabel terikatnya, dengan asumsi variabel lain konstan yaitu :

1. Koefisien regresi variabel $X_{1}$ bertanda positif menunjukkan adanya hubungan yang positif dari variabel supervisi yang menyebabkan kenaikan sebesar 0.381 dan signifikan untuk probability-t sig 0.046 (Signifikan untuk $\alpha<0.10$ ) terhadap kinerja guru.

2. Koefisien regresi variabel $\mathrm{X}_{2}$ bertanda positif menunjukkan adanya hubungan positif dari variabel kompetensi yang menyebabkan kenaikan sebesar 0.532 dan signifikan untuk probability $t$ sig 0.002 atau Signifikan untuk $\alpha<0.01$ terhadap kinerja guru.

Melalui penduga ini dapat dijelaskan, bahwa kompetensi memberikan indikasi pengaruh yang relatif lebih tinggi dari pada supervisi. Pengaruh simultan tersebut, diprediksikan untuk penduga constanta adalah positif sabesar 7.289 dengan probability t-sig (0.087) atau signifikan untuk $\alpha<0.10$. Artinya, secara simultan kedua variabel prediktor tersebut memberikan dampak positif terhadap kinerja guru. Namun, memperhatikan penduga signifikansi constanta $(0,087)$, dan signifikan untuk $\alpha<0.10$. Fenomena ini menggambarkan, bahwa prediksi naiknya kinerja guru, namun tidak didukung oleh system Operasional Prosedur (SOP) sekolah yang baik. Lebih jelasnya perhatikan tampilan tabel dibawah ini :

Tabel 1: Anova Pengaruh Secara Simultan Supervisi Dan Kompetensi Terhadap Kinerja Guru

\begin{tabular}{cccccc}
\hline Model & Sum of Squares & $d f$ & Mean Square & $F$ & Sig. \\
\hline Regression & 1983.522 & 2 & 991.761 & & \\
1 Residual & 925.188 & 28 & 33.042 & 30.015 & .000 \\
Total & 2908.710 & 30 & & & \\
\hline
\end{tabular}

Keterangan:

a Predictors: (Constant), Kompetensi, Supervisi

b Dependent Variable: Kinerja 
Jurnal Sekolah Dasar : Elementary School Journal, 1 (3), September 2018, pp. 1 - 10

Tabel 2 : Koefisien Regresi Pengaruh Secara Simultan Supervisi Dan Kompetensi Terhadap Kinerja Guru

\begin{tabular}{|c|c|c|c|c|c|}
\hline \multirow{2}{*}{ Model } & \multicolumn{2}{|c|}{$\begin{array}{c}\text { Unstandardized } \\
\text { Coefficients }\end{array}$} & \multirow{2}{*}{$\begin{array}{c}\begin{array}{c}\text { Standardized } \\
\text { Coefficients }\end{array} \\
\text { Beta }\end{array}$} & \multirow{2}{*}{$t$} & \multirow{2}{*}{ Sig. } \\
\hline & $B$ & Std. Error & & & \\
\hline 1 (Constant) & $\begin{array}{r}7.28 \\
9\end{array}$ & 6.778 & & 1.075 & .087 \\
\hline Supervisi & .381 & .203 & .363 & 2.373 & .046 \\
\hline Kompetensi & .532 & .183 & .526 & 3.444 & .002 \\
\hline
\end{tabular}

Keterangan:

a Dependent Variable: Kinerja

Lebih lanjut dapat dijelaskan, bahwa secara simultan kedua variabel tersebut mampu memprediksikan pengaruh yang positif dan signifikan untuk $\alpha<0.01$ (Perhatikan Probability $f$ - sig, 0.000), dan mampu pula memberikan kontribusi yang cukup kuat terhadap kinerja guru, perhatikan $R$-Square pada tampilan tabel $1.3(R$ Square $=0.682$ dengan estimasi residual yang explaned Residual atau sebesar $5.74825)$, sedangkan sisanya atau $32 \%$, adalah sebagai Estimasi residual yang Un explaned Residual yang dipengaruhi oleh variabel lain di luar model, namun pada waktu investigasi lapangan dilakukan adalah profesionalisme. Untuk lebih jelasnya pengaruh simultan supervisi dan kompetensi seperti telah diuraikan diatas, dapat dilihat dalam tabel 1.3. dibawah berikut:

Tabel 3. Model Summary Pengaruh Secara Simultan Supervisi Dan Kompetensi Terhadap

\begin{tabular}{|c|c|c|c|c|c|c|c|c|c|}
\hline \multirow[b]{2}{*}{ Model } & \multirow[b]{2}{*}{$R$} & \multirow[b]{2}{*}{ R Square } & \multirow[b]{2}{*}{$\begin{array}{l}\text { Adjusted } R \\
\text { Square }\end{array}$} & \multirow[b]{2}{*}{$\begin{array}{l}\text { Std. Error of the } \\
\text { Estimate }\end{array}$} & \multicolumn{5}{|c|}{ Change Statistics } \\
\hline & & & & & $\begin{array}{c}R \text { Square } \\
\text { Change }\end{array}$ & $\begin{array}{c}F \\
\text { Change }\end{array}$ & $d f 1$ & $d f 2$ & $\begin{array}{c}\text { Sig. F } \\
\text { Chang } \\
e\end{array}$ \\
\hline 1 & .826 & 682 & .659 & 5.74825 & 682 & 30.015 & 2 & 28 & .000 \\
\hline
\end{tabular}

Keterangan:

a Predictors: (Constant), Kompetensi, Supervisi

b Dependent Variable: Kinerja

\section{Pengaruh Parsial Supervisi Terhadap Kinerja guru}

Sebelumnya, dijelaskan bahwa secara simultan variabel supervisi dan kompetensi berpengaruh positif dan signifikan terhadap kinerja guru. Hal yang menarik adalah, dalam kondisi situasional dan parsial, apakah variabel supervisi mampu memberikan pengaruh yang positif dan optimal terhadap kinerja guru. Melalui persamaan model regresi parsial, terlihat arah hubungan yang dihasilkan dari variabel bebas terhadap variabel terikatnya, dengan asumsi variabel lain konstan yaitu : $\hat{y}=25.054+0.789(X 1)$ $+e$

Perhatikan, koefisien model regresi parsial, dimana variabel X1 bertanda positif menunjukkan adanya hubungan yang positif dari variabel supervisi yang menyebabkan kenaikan sebesar 0.789 , dan signifikan untuk probability t-sig 0.000 (Signifikan untuk $\alpha$ $<0.01)$ terhadap kinerja guru. Lebih jelasnya perhatikan tampilan tabel dibawah ini : 
Tabel 4 Koefisien Regresi

Pengaruh Secara Parsial Supervisi Terhadap Kinerja Guru

\begin{tabular}{|c|c|c|c|c|c|c|c|}
\hline & \multirow{2}{*}{ Model } & \multicolumn{2}{|c|}{$\begin{array}{c}\text { Unstandardized } \\
\text { Coefficients }\end{array}$} & \multirow{2}{*}{$\begin{array}{c}\begin{array}{c}\text { Standardized } \\
\text { Coefficients }\end{array} \\
\text { Beta }\end{array}$} & \multirow{2}{*}{$t$} & \multirow{2}{*}{ Sig. } & \\
\hline & & $B$ & Std. Error & & & & \\
\hline \multirow{2}{*}{1} & (Constant) & 25.054 & 4.726 & & 5.513 & & .000 \\
\hline & Supervisi & .789 & .166 & .740 & 5.920 & & .000 \\
\hline
\end{tabular}

Ketarangan:

a Dependent Variable: Kinerja

Memperhatikan kembali, tampilan tabel diatas menunjukkan bahwa supervisi mempunyai pengaruh yang positif terhadap kinerja guru. Lebih lanjut dapat dijelaskan, bahwa secara parsial variabel supervisi mampu memprediksikan pengaruh yang positif dan signifikan untuk $\alpha<0.01$ (perhatikan probability t-sig, 0.000), dan mampu pula memberikan kontribusi yang cukup kuat terhadap terhadap kinerja guru, perhatikan RSquare pada tampilan tabel 1.5 (R-Square $=0.547$ dengan estimasi residual yang explaned Residual atau sebesar 6.73928). Kondisi ini juga menjelaskan, bahwa supervisi secara parsial memberikan pengaruh positif terhadap kinerja guru dengan kontribusi sebesar $0.55 \%$. Melihat, kontyribusi yang dihasilkan hanya 55\%, maka dapat dipertegas dalam temuan penelitian ini, dalam kondisi yang situasional supervisi belum mampu menghasilkan kontribusi yang optimal terhadap kenaikan kinerja guru. Lebih jelasnya pengaruh parsial supervisi seperti telah diuraikan diatas, dapat dilihat pada tampilan tabel berikut:

Tabel 5: Model Summary

Pengaruh Secara Parsial Supervisi Terhadap Kinerja Guru

\begin{tabular}{|c|c|c|c|}
\hline \multirow{2}{*}{ Model } & & & Change Statistics \\
\hline & Square & $R$ Square the Estimate & $\begin{array}{l}R \text { Square } F \\
\text { Change Change df1 df2 Sig. F Change }\end{array}$ \\
\hline
\end{tabular}

$\begin{array}{llllllllll}1 & .740 & .547 & .532 & 6.73928 & .547 & 35.043 & 1 & 29 & .000\end{array}$

Keterangan:

a Predictors: (Constant), Supervisi

b Dependent Variable: Kinerja

\section{Pengaruh Parsial Kompetensi Terhadap Kinerja guru}

Hal yang sama dengan variabel supervisi, apakah variabel kompetensi berpengaruh positif dan signifikan, dan juga menghasilkan kontribusi yang optimal terhadapp kinerja guru. Memperhatikan model temuan parsial, dengan asumsi variabel lain konstan yaitu : $\hat{y}=26.473+0.944(X 2)+e$

Perhatikan koefisien model parsial, dimana variabel X2 bertanda positif menunjukkan adanya hubungan yang positif dari variabel kompetensi yang menyebabkan kenaikan sebesar 0.944 dan signifikan untuk probability t- sig 0.000 (Signifikan untuk $\alpha<0.01$ ) terhadap kinerja guru. Hal ini dapat diartikan, kompetensi memberikan pengaruh yang positif dan signifikan terhadap peningkatan kinerja guru SMPN 1 Bekasi. Untuk lebih jelasnya perhatikan tampilan tabel berikut: 
Tabel 6 : Koefisien Regresi Pengaru Secara Parsial Kompetensi

Terhadap Kinerja Guru

\begin{tabular}{|c|c|c|c|c|c|c|}
\hline & \multirow{2}{*}{ Model } & \multicolumn{2}{|c|}{$\begin{array}{c}\text { Unstandardized } \\
\text { Coefficients }\end{array}$} & $\begin{array}{l}\text { Standardized } \\
\text { Coefficients }\end{array}$ & \multirow{2}{*}{$t$} & \multirow{2}{*}{ Sig. } \\
\hline & & $B$ & Std. Error & Beta & & \\
\hline \multirow{2}{*}{1} & (Constant) & 26.473 & 7.186 & & 10.623 & .000 \\
\hline & Kompetensi & .944 & 138 & .786 & 7.849 & .000 \\
\hline
\end{tabular}

Keterangan:

a Dependent Variable: Kinerja

Model temuan prediksi, berpengaruh positif dan signifikan untuk $\alpha<0.01$ (Perhatikan probability t-sig, 0.000), dan mampu pula memberikan kontribusi yang cukup kuat terhadap terhadap kinerja guru, perhatikan R-Square pada tampilan tabel 1.7 (R-Square $=0.618$, atau $61 \%$, dengan estimasi residual yang explaned Residual atau sebesar 6.19006). Namun, melihat kontribusi yang dihasilkan hanya $61 \%$, hal ini mempertegas temuan penelitian, bahwa dalam kondisi situasional kompetensi belum mampu memberikan kontribusi yang optimal terhadap peningkatan kinerja guru. Lebih jelasnya pengaruh parsial kompetensi seperti telah diuraikan diatas, dapat dilihat dalam tabel 7. berikut:

Tabel 7: Model Summary

Pengaruh Secara Parsial Kompetensi Terhadap Kinerja Guru

\begin{tabular}{|c|c|c|c|c|c|c|c|c|c|}
\hline \multirow[b]{2}{*}{ Model } & \multirow[b]{2}{*}{$R$} & \multirow[b]{2}{*}{$R$ Square } & \multirow[b]{2}{*}{$\begin{array}{l}\text { Adjusted } R \\
\text { Square }\end{array}$} & \multirow[b]{2}{*}{$\begin{array}{l}\text { Std. Error of } \\
\text { the Estimate }\end{array}$} & \multicolumn{5}{|c|}{ Change Statistics } \\
\hline & & & & & $\begin{array}{l}R \text { Square } \\
\text { Change }\end{array}$ & $\begin{array}{c}F \\
\text { Change }\end{array}$ & $d f 1$ & $d f 2$ & $\begin{array}{l}\text { Sig. } F \\
\text { Change }\end{array}$ \\
\hline 1 & .786 & .618 & .605 & 6.19006 & .618 & 46.912 & 1 & 29 & .000 \\
\hline
\end{tabular}

Keterangan:

a Predictors: (Constant), Kompetensi

b Dependent Variable: Kinerja

\section{KESIMPULAN}

Berdasarkan hasil temuan model prediksi simultan dan parsial yang digunakan pada kesempatan ini, maka diperoleh beberapa kesimpulan sebagai berikut:

1. Secara simultan supervisi dan kompetensi berpengaruh positif, relatif cukup kuat dan signifikan terhadap Kinerja guru SMPN 1 Bekasi. Hal tersebut ditunjukkan dengan perolehan R-Square sebesar $68 \%$., sedangkan sisanya (32\%) dipengaruhi oleh faktor atau variabel lain di luar model temuan, dan teridentifikasi sebagai variabel profesional guru.

2. Secara parsial supervisi berpengaruh positif, relatif cukup kuat dan signifikan terhadap kinerja guru pada SMPN 1 Bekasi. Hal tersebut ditunjukkan dengan perolehan R-Square sebesar $55 \%$. (kontribusi yang dihasilkan tidak optimal terhadap kenaikan kinerja guru).

3. Secara parsial kompetensi berpengaruh positif, relatif kuat dan signifikan terhadap kinerja guru pada SMPN 1 Bekasi. Hal tersebut ditunjukkan dengan perolehan RSquare sebesar $62 \%$. Kontribusi yang dihasilkan tidak optimal terhadap kenaikan kinerja guru. Namun, lebih baik dengan variabel supervisi. 
Melihat dari kesimpulan diatas menunjukkan, variabel supervisi dan kompetensi secara simultan berpengaruh positif dan signifikan terhadap kinerja guru SMPN 1 Bekasi tahun ajaran 2016/2017. Namun, memperhatikan koefisien variabel yang relatif kecil, dan kontribusi yang dihasilkan tidak dominan (> 80\%). Diusulkan, sebagai masukan adalah sebagai berikut:

1. Memperhatikan penduga model, secara simultan supervisi dan kompetensi terhadap kinerja guru, dimana penduga signifikannya yang relatif kurang baik, ada pada ambang batas maksimal $0,10 \%$. Namun, masih pada tahap toleransi kebenaran. Diusulkan, Segera membangun kembali kebijakan supervisi dan kompetensi guru yang sejalan dengan perkembangan IPTEK. Hal itu dapat dilakukan melalui, dalam konteks; kebijakan supervisi, perlu melakukan optimalisasi pengawasan baik itu secara berkelompok, dan dilakukan secara intensif dan berkala, baik itu menyangkut dari kinerja individu dan kelompok guru. Dala konteks; kebijakan kompetensi, pihak manajemen sekolah segera meningkatkan kemampuan dan wawasan para guru yang merata untuk semua guru, hal itu dapat dilakukan melalui meningkatkan kemampuan kerja guru sesuai dengan bidang keahlian masingmasing guru, dan secara berkala memberikan masukan kemampuan kerja melalui seminar, loka karya, menulis jurnal ilmiah dan melakukan penelitian yang up to date perkembangan pendidikan terkini.

2. Memperhatikan kontribusi parsial supervisi dan kompetensi yang relatif kurang baik, diusulkan variabel prediktor ini tidak dijadikan suatu kebijakan yang strategis terhadap peningkatan kinerja guru ke depan, sebelum adanya perbaikan untuk masing-masing faktor atau variabel yang diusulkan.

\section{DAFTAR PUSTAKA}

A W. Sturges. 1998. Dasar-Dasar Proses Belajar Mengajar. Sinar Baru Algensio. Bandung. 2004. hal. 147.

Algivari. 1997. Pengantar Metode Statistik II. Jakarta: PT. Pustaka LP3ES.

Anwar Prabu Mangkunegara. 2006. Evaluasi Kinerja SDM. Bandung: PT Refika Aditema. Cet. Ke-10.

Bolla 1998. Administrasi Manajemen dan Kepemimpinan Pendidikan.Jakarta: Bumi Aksara.

David C. McClelland. 1997. Testing for Competence rather than Intelligence. New York. Allyn dan Bacon

Dede Rosyada. 2004. Paradigma Pendidikan. Demokratis sebuah model perlibatan Masyarakat dalam Penyelenggaraan Pendidikan. Jakarta: PT Kencana

Dewi Haryati 2007 Pengaruh Diklat Dan Supervisi Kepala Sekolah Terhadap Kinerja Pengelola Unit-Unit Program Produktif Studi Kasus Pada Smkn 2 Cikarang Barat. Program Pasca Sarjana Magister Manajemen Universitas Krisnadwipayana. Jakarta

Gordon. 1999. Administrasi Pendidikan. Mutiara Sumber Widya

Gordon. 1999. Pengelolaan Pendidikan Dasar. Jakarta: Dirjen Dikdasmen.

Harun Al Rasyd. 1998. Reliabilitas dan Validitas Pustaka Pelajar. Jogyakarta

Hasibuan. 2001. Psikologi Pendidikan dan Evaluasi Belajar. Jakarta: Gramedia..

Ivor K. Davies 1987. School Development Series: Improving Education. London: Cassel. 
Kennedy P. 1995. Organisasi Sekolah dan Pengelolaan Kelas. Jakarta : CV. Haji Mas Agung.

Kutner H. Michael. 2007. Sample Survey Methode and Theory. Vol. I. New York: John Willey \& Sons. Inc.

Lind. 2002. Korelasi Dan Analisis Regresi Berganda. Nur Cahaya.

Moh. Rifai. 1995. Administrasi dan Supervisi Pendidikan. Bandung : Jemmars

Moh. Uzer. 2003. Analisis Kebijakan Pendidikan Suatu Pengantar. Bandung: PT. Remaja Rosda Karya

Oteng Sutisna. 1997. Administrasi Pendidikan Dasar Teoritis Untuk Praktek Profesional. Jamrsa. Bandung.

Pidarta. 1996. Peningkatan Profesionalisasi Jabatan Guru (Makalah). Jakarta: Pusat Informatika Depdikbud.

Prabu. A.A Mangkunegara Anwar. 2000. Manajemen Sumber Daya Manusia. Bandung:PT. Rosdakarya.

Purwanto. M. Ngalim. 2004. Administrasi dan Supervisi Pendidikan. Bandung: Remaja Rosdakarya

Rigdon dan Ferguson . 1991. Sampling Techniques. 2nd. Ed. New York: John Willey \& Sons

Sergiovanni dan Starrat. 1999. Supervision A Redefinition. New York. McGraw-Hill Inc

Siti Salbiah 2008 Pengaruh Gaya Kepemimpinan Dan Kompensasi Terhadap Kinerja Guru (Studi Kasus Pada Smkn 2 Cikarang Barat)". Program Pasca Sarjana Magister Manajemen Universitas Krisnadwipayana. Jakarta

Slovin. 2001. Sampling: A Quick Reliable Guide to Practical Statistics. New Yoek: Simon and Schuster.

Spencer. 2001. Strategi Sukses Dalam Karir: Strategis For Career Success. alih bahasa Anna W. Bangun (Jakarta: Elex Media Komputindo).

Sudrajat. Ahmad. 2007. Budaya Organisasi Sekolah. Jurnal Journal of Instructional Psycology. Vol. 29. No. 3. 2007 Emporwerment : Teacher Perceptions. Aspirations and Effecasy

Sugiyono. 2001. Metode Penelitian Bisnis. Alfabeta. Bandung.

Suryo. Subroto. B. 1997. Proses Belajar Mengajar di Sekolah. Jakarta: Rineka Cipta

Tilaar. H.A.R.. 1999. Manajemen Pendidikan nasional Kajian Pendidikan Masa Depan. Bandung: Remaja Rosdakarya.

Travers. 2001. Elementary Survey Sampling. New York: Wadsworth Pub. Co. 